\title{
KOGNITIIVNE AUTONOOMIA - KAS HÄÄBUV IDEAAL?
}

\author{
TIIU HALLAP
}

$\mathrm{K}$ ui XVIII sajandi inglise kirjamees Samuel Johnson töötas raamatu kallal, mis rääkis inglise luuletajatest, pakkus tema sõber James poet Alexander Popei. Johnson lukkas pakumise poet Alexander Pope'i. Johnson lükkas pakkumise tagasi järgmiste sonnadega: „Kui teadmisi sajaks nagu vihma, siis ma sirutaksin oma käe välja; kuid ma ei võtaks vaevaks seda ise otsima minna."

Äsja toodud lõik pärineb New Yorgi ülikooli poliitikateoreetiku ja filosoofi Russell Hardini kirjutisest pealkirjaga „Kui teadmisi sajaks” (Hardin 2003). Kujutluspilt teadmistevihmas seisvast inimesest, kes aeg-ajalt kätt välja sirutab, et haarata pihku mõni teadmisetükk, on intrigeeriv. Tekib tahtmine uurida, millised mõttekäigud on selle kujundi taga ja kuhu nad viivad.

$* * *$

Hardini arutelu üks märksõna on tänavaepistemoloogia. Ta mõtleb järgmist. Tänapäeval pole inimestel aega uurida kas või murdosa nende asjade tõesust, mida neil on vaja teada. Teadmise põhiallikas on seepärast kuulujutt. Tänavateadmine pärineb igasugustelt näilistelt või tõelistelt ekspertidelt, alates keelepeksust kuni teatmeteoste ja ajalehtedeni. Ka teadlase jaoks on teistelt kuuldu ja teiste väidetu ülioluline teadmise allikas. Ei saa ju iga kord ise kontrollida, kas kõik mõõteriistad on korras või kas katseklaasi sisu vastab sildile.

Nii ongi ökonoomne. Tõtt-öelda ei peakski inimest ülearu huvitama, kuidas asjad töötavad. Mõttekam on teaduse saavutusi kasutada, kui neid mõista. Nagu Hardin ütleb: „Ma istun lennukisse ja see lendab üle ookeani - kes teab täpselt, kuidas ja miks?" See on täiendav põhjus, miks iseseisva teadmise otsimise asemel on mõttekas koguda asjalikke kuulujutte. Varem või hiljem sõelume neist mingi tulemuse välja ning siis teadmine lihtsalt $\mathrm{j} u \mathrm{htub}$ meiega. Teadmine on samas kategoorias usalduse ja uskumisega. Ka neid me ei vali, vaid need juhtuvad meiega.

Selle suhtumise taustal naerab Hardin välja briti filosoofia suurkuju, XVII sajandi tunnetusteoreetiku ja poliitikafilosoofi John Locke’i vaatekoha. Locke kritiseeris teravalt usaldusele ja uskumisele toetuvat tunnetushoiakut. Toon näitena ühe tema iseloomuliku ütluse:

Tõelist teadmist on meil vaid nii palju, kui palju me ise tõde vaagime ja mõistame. Teiste inimeste arvamuste hõljumine meie peas ei tee meid silpigi rohkem teadvaks, isegi kui need arvamused on tõesed. [---] See, mida inimene lihtsalt usub ja usalduse alusel omaks võtab, on ainult raasukesed, mis [---] ei lisa midagi inimese teadmistevarudele. [---] Säärane laenatud rikkus on nagu 
haldjalt saadud raha muinasloos: algul näeb see välja nagu kuld, kuid hiljem muutub puulehtedeks ja tolmuks. (Locke 1975 [1689]: 101)

Selline suhtumine on Hardini arvates absurdne. Inimesele on eriomane teada asju, mida ta pole ise näinud. Ahvi kohta võib öelda, et „kui ahv ei näe, siis ahv ei tea". Ülistades üksikisiku iseseisvat kriitilist mõtlemist, ülistab Locke just selliste ahvide võhiklust, kes oma ninast kaugemale ei näe. Tema hoiak on Hardini järgi otseselt kahjulik, sest pärsib progressi. Tsivilisatsioon on edenenud ainult tänu sellele, et me ei nõua, et meie teadmine rahuldaks Locke'i standardeid.

****

Käesolevas artiklis arutlen Locke’i ideaali üle ühe konkreetse nurga alt. Esimese mõtteuiuna tekkis mul küsimus, kas üksikisiku tunnetusliku iseseisvuse kahanemine hakkab kunagi ka liberaalseid ideaale mõjutama. Arenenumates ühiskondades näib üksikisiku vabadus järjest kasvavat. Kuid teadmine killuneb ja kollektiviseerub üha enam. Intellektuaalses sfääris tundub kohati, just nagu toimuks areng sünteesivõimeliselt üksikisikult pigem tillukese kognitiivse putuka suunas. Üha rohkem kõlab soovitusi oma mõistus ja hinnang delegeerida teistele, parematele mõistustele - inim- või masinekspertidele. ${ }^{1}$ Kuidas suhestuvad need kaks suundumust - üldise isikuvabaduse kasv ning tunnetusliku autonoomia kahanemine ? Et sellele vastata, selgitan kõigepealt filosoofiliste isikuautonoomiateooriate paari-kolme lähtemõistet.

Isikuautonoomia ehk isiklik autonoomia määratletakse kui võime olla sina ise, võime ise juhtida oma elu. Isejuhtimine tähendab, et inimene juhindub sellistest soovidest, motiividest, kaalutlustest, mida tajub enda omana ja mis pole manipulatiivsete või moonutavate välisjõudude tulemus. Inimest käivitavad jõud on n-ö autentse mina osa.

Inimene võib olla autonoomne paljudes oma elu valdkondades või ainult mõnes, autonoomia võib niisiis olla globaalsem või lokaalsem. Reeglina arvatakse, et mis tahes autonoomiateooria peab tunnistama, et enamikul täiskasvanutest on olemas minimaalne baasautonoomia, mis üldse lubab talle omistada mingeid õigusi ja kohustusi. Samas täielik autonoomia võib olla teostamatu ideaal või äärmiselt harva esinev omadus. ${ }^{2}$

\footnotetext{
${ }^{1}$ Aeg-ajalt esineb muidugi ka sellise hoiaku kriitikat. Masinekspertide kohta nt kas või õiguskantsler Ülle Madise sõnavõtt: „On ju mugav lülitada GPS sisse (ja koos sellega oma mõistus välja). [---] Kas masin, see valgustatud monarh, oskab tõesti head halvast ja head veelgi paremast eristada? [---] usutakse tõemeeli, et masin on täiuslik, tark algoritm suudab ka ühiskonna-asju meist paremini otsustada." (Madise 2018)

${ }^{2}$ Eeltoodud vaimus piiritleb autonoomia mõiste näiteks John Christman (2015), ent samalaadseid määratlusi leiab teistestki tekstidest. Kuid autonoomia mõistega on lood tegelikult keerulised. Kuigi viimastel aastakümnetel on autonoomia mõiste muutunud väga mõjukaks reas praktilistes kontekstides, nagu näiteks meditsiinieetika, ärieetika (reklaami kui „ajupesu” lubatavus), põhiseaduslikud küsimused, mis seostuvad privaatsuse ja sõnavabadusega, üldisemalt mis tahes paternalistlik sekkumine üksikisiku ellu, liberaalse hariduse olemus jne, alustavad paljud arutlused tõdemusest, et see mõiste on „parimal juhul ähmane” (May 1994: 133). See kas ei eristu piisavalt vabaduse mõistest või sellel on nii palju erinevaid modifikatsioone ja kasutuskontekste, et mingist ühtsest mõistelisest tuumast ehk ei saagi rääkida. Isaiah Berlin kõneleb oma tuntud „Vabaduse
} 
Isikuautonoomiast kirjutajad analüüsivad asju enamasti mingit laadi hierarhilise mudeli raames. Hierarhia alumisel astmel on inimese esmatasandi soovid ja motiivid, ülemisel astmel n-ö kõrgemad mõtlused, refleksioon esmatasandi üle. Et mitte jääda abstraktseks, toon argise näite. Kui inimesel tekib kiusatus võtta üks naps või koguni kaks, siis see on esmatasandi iha. Mõnel juhul minnakse pärast lühikest arupidamist baarikapi juurde. Mõnel juhul on arupidamine välistatud, sest inimesel on alkoholiga kompulsiivne suhe. Ta on alati sunnitud napsu võtma, niipea kui kihk tekib. Mõnel juhul jääb inimene kauaks mõtlema, kas see konkreetne naps ja napsuvõtmine üldisemalt sobib tema huvidega pikas vaates.

Hierarhiline mudel ütleb, et autonoomia tähendab põhiliselt kahte asja: 1) et inimene soovi tekkides siirdub kõrgemale mõtlustasandile ja 2) et ta pärast mõtlust s a mastub oma esmatasandi sooviga; ta kiidab selle heaks või vähemalt tunnistab omaks, autentseks. ${ }^{3}$ Vaieldakse selle üle, mida samastumine endas täpselt sisaldab. Inimene võib oma soovi tunnistada, aga seda mitte heaks kiita; niisiis võib küsida, kas soovi autentsuseks on piisav mõistuse leige heakskiit või peab see tulema kogu südamest. Lisaks samastumise olemusele on probleem ka see, kus kohas kõrgemate mõtluste protsess lõpeb. Kas kõrgem mõtlus napsuvõtmise üle tegelikult ikka oli autentne? Võib-olla tuleks selle üle mõtiskleda veelgi kõrgemal mõtlustasandil. Sest kui inimese esmatasandi soovid on manipuleeritud või moonutatud (näiteks ajupesuga), miks ei või ka kõrgema mõtluse tulemused seda olla? Ja äkki peegeldavad esmatasandi soovid ja ihad inimese autentset mina isegi paremini kui pealtnäha ratsionaalsemad hinnangud. See on võimalik, kuid autonoomiateoreetik nii ei arva.

kahes mõistes" (1998: 53) sisuliselt autonoomiast, kuid eelistab nimetada seda positiivseks vabaduseks. Muuhulgas märgib ta vabaduse mõiste paljutahulisuse kohta: „Ma ei tahaks kõnelda selle mitmepalgelise sõna ajaloost ega enam kui kahesajast tähendusest, millele on osutanud ideedeajaloolased" (Berlin 1998: 36). Sellega võrreldes on autonoomia mõistega (kui seda eraldiseisvana tunnistada) lood pisut paremad. Mõjukas on Joel Feinbergi käsitlus (1989), kus on eristatud nelja autonoomia põhitähendust; teiste autorite taksonoomiates võib neid olla ka kaks, kaheksa või isegi kakskümmend. Kuna pole kahtlust, et vabaduse ja autonoomia mõistete vahel on tihe side, ükskõik kuidas nende vahekord „viimses analüüsis” välja näeb, siis kombinatsioonide arv kuni 20 erinevast autonoomia tähendusest ja kuni 200 vabaduse tähendusest on ilmselt astronoomiline. Christman (1989: 4) märgib võrdlevalt, et kuni suhteliselt hiljutise ajani on vabaduse mõiste siiski olnud palju põhjalikumalt läbi analüüsitud kui autonoomia mõiste. Kas vabaduse sõna tähendusaspektide rohkus tuleneb sellest, et seda ideed on nii palju ja nii sügavuti analüüsitud - või on seda ideed nii palju analüüsitud seepärast, et võimalikke tähendusaspekte tundub algusest peale olevat nii palju? Vastust teab vaid tuul... Ekskursi lõpetuseks olgu nimetatud mõned tähtsamad allikad ja autorid. Palju viidatud käsitlus autonoomia mõiste teoreetilistest ja praktilistest aspektidest, eriti eetika kontekstis, on Dworkin (1988). Uuemaid arenguid autonoomiaaruteludes vt Taylor (2008), Christman ja Anderson (2005) ning Christman (2015). Autonoomia mõiste ajalugu käsitleb Schneewind (1998). Immanuel Kanti mõju autonoomiateooriatele on olnud väga suur, kuid tema enda arusaam autonoomiast oli oluliselt teistsugune kui enamikul tänapäeva autoritel. Seda küsimust käsitlev uusim kogumik on Sensen 2013 (eriti Thomas Hilli artikkel „Kantian autonomy and contemporary ideas of autonomy” selles kogumikus).

${ }^{3}$ Väidetavalt on selline autonoomiamudel, mis nõuab „teist järku” samastumist „esimest järku" soovidega, kõige mõjukam (Christman, Anderson 2005: 3). Selle mudeli pakkusid algselt välja Gerald Dworkin (1988, 1989) ja Harry Frankfurt (1987). Olgu märgitud, et Frankfurti arutluste kontekst oli tahtevabadus, mitte autonoomia, ent nende arutluste loogika võeti üle autonoomiakirjandusse. 
Igal juhul nõuab autonoomia teatud mõistuspärast protseduuri. Tähtis on, et inimene ei järgi oma impulsse pimesi. Protseduur peab olema, kuid soovide sisu pole oluline. Sellist lähenemist tuntaksegi protseduurilise autonoomiakäsitluse nime all ja selles on autonoomia väärtusneutraalne mõiste. Niihästi kõva napsuvend kui ka kõva karsklane võivad olla alkoholi aspektis autonoomsed, juhul kui nad oma soovi võtta või mitte võtta korralikult mõtestavad.

Kuid kas tõesti soovide sisu pole oluline? Protseduurilises käsitluses peab autonoomseks tunnistama ka inimesed, kes teadlikult valivad väga piiratud eluvõimalustega olukorra. Gerald Dworkin väljendab seda nii:

Autonoomne inimene võib olla türann või ori, pühak või patune, juht või järgija. [---] Autonoomia idees ei ole midagi, mis takistaks inimest ütlemast: ma tahan olla selline inimene, kes käib teiste käsu järgi. Ma määratlen ennast orjana ning pooldan vastavaid hoiakuid ja eelistusi. Minu autonoomia seisneb ori olemises. (Dworkin 1988: 29, 129)

Osa autoreid sellega ei lepi. Mitteprotseduurilised, s i s u l i s ed autonoomiamudelid ei pea teadlikult orjuse või heroiinisõltluse valinud inimest autonoomseks. Siis aga pole autonoomia omistamine väärtusneutraalne. Autonoomseks osutuvad ainult teatavat laadi elustiilid - need, mis on mingist poliitilisest või moraalsest vaatepunktist vastuvõetavad.

$* * *$

Siit edasi on kohane küsida, milline on autonoomse isiku roll liberaalses ilmavaates. 2005. aastal ilmunud John Christmani ja Joel Andersoni toimetatud kogumik „Autonoomia ja väljakutsed liberalismile” (2005) käsitleb just seda küsimust. Autonoomia mõiste mängib nende autorite arvates liberaalsetes mõttekonstruktsioonides mitmeid eri rolle. Nimetan kahte.

Esiteks, autonoomne inimene on sageli n-ö mudelinimene, kelle vaatepunkti kasutatakse selleks, et põhjendada poliitilisi printsiipe. Näiteks ühiskondliku kokkuleppe ideel põhinevad õigluseteooriad eeldavad enamasti, et kokkuleppe kujutletavateks sõlmijateks on just autonoomsed inimesed. Kui nad seda poleks, kui kokkuleppijate soovid ja motiivid oleksid näiteks tugevast ajupesust moonutatud, vaevalt saaks neist lähtuv mõttearendus mingit põhimõtet seadustada.

Teiseks, peavoolu liberalismi üks põhiküsimus on, mil määral on lubatav inimese valikutesse sekkuda. Mittesekkumise põhimõte ehk nn negatiivne vabadus on liberalismis täiesti keskne. Kuid ka see põhimõte on veenev vaid siis, kui inimesed on piisavalt autonoomsed. Kui inimeste soovid pole päriselt nende omad, vaid on ideoloogilise sisenduse tulemus või psühhotroopsete ainetega esile kutsutud, siis pole sugugi ilmne, miks peaks neid soove austama.

Kriitikud ründavad tänapäeval sageli autonoomse isiku eeldust liberalismis. Christmani ja Andersoni kompaktses sõnastuses:

Kommunitaarid ja identiteedipoliitikud ütlevad, et autonomism on hüperindividualistlik arusaam: eeldatakse, just nagu saaks mingi autonoomne isik eksisteerida enne, kui ta sõnastab need eesmärgid ja väärtused, mis moodustavad 
tema [---] identiteedi. Feministid väidavad, et jutt autonoomsest isikust ülistab peresidemetest sõltumatut meest. Postmodernistide arvates jutt stabiilsest ja läbipaistvast minast, kes saab teha ratsionaalseid valikuid, on lihtsameelsus, sest nüüdisaegne inimene on komplitseeritud, muutlik ja konfliktne; ning inimese motivatsioonistruktuuris on palju sellist, mis on isiku teadvuse eest varjul, moonutatud või maskeeritud kujul. (Christman, Anderson 2005: 4)

Autonoomne isik on seega kas fiktsioon või siis inimene lihtsalt ei suuda oma soovide maailma läbi valgustada. Need süüdistused on pannud liberalismi arendama „sotsiaalsemaid” autonoomiakäsitlusi. Kuivõrd autonoomia määratluses on manipulatsiooni mõistel suur roll, siis üks keeruline osaküsimus on siin sotsiaalse manipulatsiooni ja sotsiaalse mõju eristamine. Sotsiaalselt manipuleeritud soovid on üks asi, sotsiaalselt mõjutatud soovid teine. Kuidas neil vahet teha, pole selge.

****

Naasen nüüd intellektuaalse autonoomia juurde ja sõnastan eeltoodu valguses viis punkti. ${ }^{4}$

1. Hierarhiline autonoomiamudel kirjeldab inimest vertikaalselt. On esmatasandi ihad, siis kõrgemad mõtlused, siis võib-olla veelgi kõrgemad mõtlused, mis püüavad aru saada, kas eelmised mõtlused olid autentsed, ja nii edasi, halvemal juhul kuni lõpmatuse ja hullumeelsuseni välja.

Kuid mõelda saab ka horisontaalselt. Ja nimelt: analüütiline vaimufilosoofia kasutab sageli mudelit, kus inimest nähakse uskumuste ja soovide süsteemina. Selles mudelis ei huvituta inimvaimu varjatud süvakihtidest ega ka kõrgema mõtluse kihtidest, vaid sellest, mis on ilmne ja pinnal. See on ka argine rahvapsühholoogiline tasand. Mul on soov reisida Argentina pampadesse ning mul on uskumused selle kohta, kus on Argentina ja mis on pampa. Nii soovidel kui ka uskumustel on semantiline sisu, kuid samas on nad olemuslikult erinevad: soovidel on liikumapanev jõud, motivatsioonienergia, uskumustel seda ei ole. Süsteem on horisontaalne, sest uskumuste süsteem ja soovide süsteem paiknevad võrdväärsena ühel tasandil, üks pole teise kohal.

${ }^{4}$ Käesolevas tekstis ei tehta erilist vahet kognitiivsel, intellektuaalsel ja „lihtsalt" autonoomial. Nagu märgitud, on autonoomia mõistel ohtralt variatsioone. Kognitiivse autonoomia termin näib olevat levinud robootikaga seotud kontekstis; intellektuaalsest autonoomiast kõneleb mõnikord teadusfilosoofia nn voorusepistemoloogiline haru. Ehkki viimasel on oma tugev eripära, kõlavad voorusepistemoloogilised arutelud kokku ka siinses kirjutises käsitletud teemadega. Nt Duncan Pritchard (2016) arutleb oma silmaga nägemise ehk isenägemise (ingl seeing it for oneself), teadmise ja mõistmise vahekorra üle. Isenägemine võib olla nii tavanägemine kui ka „intellektuaalne isenägemine” - nähtuse mõistmine omaenda tunnetusressursside abiga. Huvitav on küsimus, mismoodi hakkavad intellektuaalset autonoomiat mõjutama kõrgtehnoloogilised arengud. Adam Carter (2017) vaagib, kuidas suhtuda nn kognitiivse täiustamise (ingl cognitive enhancement) teemasse. Mõned nutiravimid, mis parandavad spetsiifilist kognitiivset sooritust, kahjustavat mõtlemise iseseisvust. Mitmesugused kognitiivsed „tellingud” võidakse miniaturiseerumise jätkudes lülitada otse ajju (nn neuromeedia tehnoloogia, vt Lynch 2016). Vikipeedia otsisõna sisestamise asemel piisab siis mõttelisest käsust. Kuid tehnoavarii korral tekkiv ühenduse kadu võib sellise tehnoloogia kasutaja jaoks olla niisama hirmus kui praegu nägija jaoks äkiline pimedaks jäämine ning tuua kaasa täieliku intellektuaalse (ja muusuguse) abituse. 
Selles pildis ei tundu vale öelda, et isiklik autonoomia puudutab eeskätt soove, intellektuaalne autonoomia aga uskumusi. Isikliku autonoomia ideaal peab soovitavaks s o ovid e süsteemi läbivalgustamist ja ,isejuhtimist”, intellektuaalse autonoomia ideaal aga us ku muste süsteemi läbivalgustamist ja „isejuhtimist”.

Kuid soovide autonoomia tundub lõputult palju lihtsamini teostatav kui uskumuste autonoomia. Ma võin püüda oma soovide hulka läbi valgustada ning neid jõukohase miinimumini viia ja see tundub ikkagi olevat tehtav. Soovide minimeerimist soovitavad nii iidsed õnneõpetused kui ka tänapäeva minimalistliku elustiili liikumine. Uskumuste hulga samalaadne minimeerimine tundub kuidagi võimatum. Juba koolisüsteem viib inimese kokkupuutesse tohutu hulga uskumustega ning seda teeb ka mis tahes tänapäevane töö. Ka kvalitatiivses mõttes näivad uskumused raskemini käsitletavad kui soovid. Kõik teadmiste valdkonnad on komplitseeritud ja nõuavad pikka eriväljaõpet. Paljude autonoomsete soovide jaoks pole aga erilist väljaõpet vaja.

2. Intellektuaalne autonoomia ei tundu üldiselt isikliku autonoomia jaoks vajalik. Isiklik autonoomia on eeskätt soovide autonoomia, kuid väga paljude soovide autentsus ei nõua uskumuste autentsust. Kui mul on autentne soov reisida Argentina pampadesse, siis ma vajan häid uskumusi Argentina ja pampade kohta, kuid need ei pea olema autonoomsed. Juba lähitulevikus on ilmselt nii, et kui hakkan reisi planeerima, siis vajutan nupule ja ütlen arvutile või seinale: „Tahan minna Argentinasse. Palun räägi, mis selleks tarvis on." Kust info siis tuleb, kes seda on kontrollinud, ei pruugi huvitada. Ka paljud teised soovid on samalaadsed ega nõua minu vaimupingutusi.

Teisalt, leidub ka soove, mille puhul autonoomsed uskumused tõesti on tarvilikud. Oletame, et inimene soovib intelligentselt hääletada. Teha kaalutud otsuse, mis arvestaks valimisprogramme, isikuomadusi, keskkonna huvisid jne. Autonoomsete uskumuste kujundamine kuulub siis tegelikult vastava soovi (nimelt, „intelligentselt hääletada”) koosseisu. Ent kui inimene soovib hääletada lihtsalt, mitte intelligentselt, siis see autonoomseid uskumusi ei nõua. Hääletamist dirigeerivad soovid võivad siis olla täielikult manipuleeritud ja läbi mõtlemata.

3. Ma oleksin tahtnud leida mingi vihje selle kohta, et intellektuaalse autonoomia kahanemine ei saa piiramatult jätkuda, sest see seab liberaalse ilmavaate ohtu. Liberalism on väga mõjukas mõttevool, ja kui kuidagi nähtuks, et oma mõistuse kasvav delegeerimine või võõrandamine kollektiivile või masinale hakkab liberaalsusele vastu töötama, aitaks see intellektuaalse autonoomia ideaali kaitsta.

Kuid esialgu sellist tulemust silmapiiril pole. Intellektuaalse autonoomia ja liberalismi vahel pole otsest, paratamatut seost. On liberaalseid autoreid, kelle jaoks pole isegi soovide autonoomia tarvilik, rääkimata uskumuste autonoomiast. Milline on inimese soovide ajalugu ja kes talle need soovid täpselt pähe pani, pole oluline. Kui tema soovid teisi ei kahjusta, siis las nad olla. Autentse, moonutustevaba mina idee võib olla suisa ohtlik, sest keegi võib hakata mulle ette kirjutama, milline minu autentne mina on, ja avada sellega ukse näiteks totalitarismile. Väljamõeldud moonutustevabast minast saab siis ise moonutuste allikas. 
4. Samal ajal ei asetu mitte kõik liberalismid intellektuaalse autonoomia suhtes ühtemoodi. Niisugused teooriad, kus vabadus on eeskätt mittesekkumine ja autonoomia (juhul kui seda üldse vajalikuks peetakse) on puhtprotseduuriline, ei näi andvat intellektuaalsele autonoomiale mingit kohta. Kuid osa liberalisme ei sõlmi ennast täielikult lahti hüveteooriast. Nii mõnelgi klassikalisel liberaalil, näiteks J. S. Millil, oli üksikisiku eneseteostus, oma potentsiaali maksimaalne arendamine kõrgemalt väärtustatud kui rohmakamad naudingud. Sellised perfektsionistlikud liberalismid saavad intellektuaalsele autonoomiale olulisema koha anda.

5. Tundub tõepärane, et inimese intellektuaalne autonoomia kahaneb tulevikus veelgi. Seda isegi juhul, kui autonoomsusideaali hakatakse rohkem hindama. Võib-olla kunagi „uue maagia” või „uue maania” taandub ning teadmise edasiandmist ja transformeerimist arusaadavale kujule väärtustatakse sama kõrgelt, kui praegu on väärtustatud uue teadmise loomine. See on kindlasti vajalik, et inimese intellektuaalne autonoomia saaks suureneda. Kuid kvantitatiivne trend intellektuaalse autonoomia kahjuks jääb vist püsima ka siis, sest teadmiste hulk ja keerukus kasvab võrratult palju kiiremini kui üksikisiku võime neid teadmisi mõtestada. Selles mõttes ei tundu Locke’i ideaali tulevik väga helge. Ent ideaali olemusse kuulub muidugi, et ta ei pea olema täielikult teostatav. Tõsiasi, et meie ajastul intellektuaalset autonoomiat väga ei hinnata, on võib-olla hea põhjus selle ideaali üle mõelda. Täpselt samuti, nagu näiteks keskkonnakaitse ideaalid muutuvad eriti värskeks ja akuutseks just siis, kui keskkonnaga on halvasti - mitte siis, kui kõik on kõige paremas korras.

\section{Kirjandus}

B e r lin, Isaiah 1998. Valik esseid. Tlk Erkki Sivonen. Tallinn: Hortus Litterarum. Carter, J. Adam 2017. Intellectual autonomy, epistemic dependence and cognitive enhancement. - Synthese. https://doi.org/10.1007/s11229-017-1549-y (1. VIII 2019).

Christman, John (toim) 1989. The Inner Citadel: Essays on Individual Autonomy. New York: Oxford University Press.

Christm a n, John 2015. Autonomy in moral and political philosophy. - Stanford Encyclopedia of Philosophy. Toim Edward N. Zalta. https://plato.stanford.edu/ entries/autonomy-moral/ (1. VIII 2019).

Christman, John, Anderson, Joel (toim) 2005. Autonomy and the Challenges of Liberalism: New Essays. New York: Cambridge University Press.

Dw orkin, Gerald 1988. The Theory and Practice of Autonomy. New York: Cambridge University Press.

Dw orkin, Gerald 1989. The concept of autonomy. - The Inner Citadel: Essays on Individual Autonomy. Toim John Christman. New York: Oxford University Press, lk 54-62.

Feinberg, Joel 1989. Autonomy. - The Inner Citadel: Essays on Individual Autonomy. Toim John Christman. New York: Oxford University Press, lk 27-53. 
Frankfurt, Harry 1987. Freedom of the will and the concept of a person. H. Frankfurt, The Importance of What We Care About. Cambridge: Cambridge University Press, lk 80-94.

Har d i n, Russell 2003. If it rained knowledge. - Philosophy of the Social Sciences, kd 33, nr 1, lk 3-24.

Hill, T. 2013. Kantian autonomy and contemporary ideas of autonomy. - Kant on Moral Autonomy. Toim Oliver Sensen. Cambridge: Cambridge University Press, lk 15-31.

L o cke, John 1975 [1689]. An Essay Concerning Human Understanding. Oxford: Oxford University Press.

Lynch, Michael P. 2016. The Internet of Us: Knowing More and Understanding Less in the Age of Big Data. London: W. W. Norton.

Ma di s e, Ülle 2018. Vimm ja vabadus. - Postimees 10. XI.

May, Thomas 1994. The concept of autonomy. - American Philosophical Quarterly, kd 31, nr 2, lk 133-144.

Pritchard, Duncan 2016. Seeing it for oneself: Perceptual knowledge, understanding, and intellectual autonomy. - Episteme, kd 13, nr 1, lk 29-42.

Schneew in d, Jerome B. 1998. The Invention of Autonomy: A History of Modern Moral Philosophy. Cambridge: Cambridge University Press.

Sensen, Oliver (toim) 2013. Kant on Moral Autonomy. Cambridge: Cambridge University Press.

Taylor, James Stacey (toim) 2008. Personal Autonomy: New Essays on Personal Autonomy and its Role in Contemporary Moral Philosophy. Cambridge: Cambridge University Press.

Tiiu Hallap (snd 1960), MA, filosoofiatõlkija, tiiuhallap@gmail.com

\section{Cognitive autonomy - a perishing ideal?}

Keywords: cognitive autonomy, personal autonomy, liberalism, John Locke, Russell Hardin

In today's world, knowledge is increasingly becoming a social, collective phenomenon. Enlightenment philosophers, notably John Locke, declared that any opinion accepted without critical scrutiny, based on pure trust and testimony of others, was worthless, whereas it seems more characteristic of our time to claim that to pursue cognitive autonomy is an obsolete ideal. It is now normal and desirable to delegate judgment in intellectual matters to special sciences, human or machine experts, opinion leaders. The agent's general personal autonomy is often (though not always) highly valued by those endorsing the liberal worldview. But it is unclear whether personal autonomy is possible without significant cognitive autonomy, or what such a situation would really mean. The present paper, taking as its startingpoint some recent literature in analytical philosophy, outlines the basic conceptual framework and suggests some points for reflection.

Tiiu Hallap (b. 1960), MA, philosophy translator, tiiuhallap@gmail.com 